Article

\title{
Concept for Improved Handling Ensures Effective Contactless Plasma Treatment of Patients with kINPen ${ }^{\circledR}$ MED
}

\author{
Veronika Hahn ${ }^{1, *}$, Daniel Grollmisch ${ }^{1,2}$, Hannes Bendt ${ }^{1}$, Thomas von Woedtke ${ }^{1,3}{ }^{(0)}$, \\ Bodo Nestler ${ }^{2}$, Klaus-Dieter Weltmann ${ }^{1}$ and Torsten Gerling ${ }^{1,4,5}$ (D) \\ 1 Leibniz Institute for Plasma Science and Technology (INP), a Member of the Leibniz Research Alliance \\ Leibniz Health Technologies, Felix-Hausdorff-Str. 2, 17489 Greifswald, Germany; \\ Daniel.Grollmisch@gmx.de (D.G.); hannes.bendt@inp-greifswald.de (H.B.); \\ woedtke@inp-greifswald.de (T.v.W.); weltmann@inp-greifswald.de (K.-D.W.); \\ gerling@inp-greifswald.de (T.G.) \\ 2 Technische Hochschule Lübeck, FB Angewandte Naturwissenschaften, Mönkhofer Weg 239, 23562 Lübeck, \\ Germany; bodo.nestler@th-luebeck.de \\ 3 Institute for Hygiene and Environmental Medicine, Greifswald University Medicine, Fleischmannstraße 8, \\ 17475 Greifswald, Germany ${ }^{4}$ Centre for Innovation Competency ZIK Plasmatis, Felix-Hausdorff-Str. 2, \\ 17489 Greifswald, Germany \\ 5 Competency Centre for Diabetes (KDK), Greifswalder Str. 11, 17495 Karlsburg, Germany \\ * Correspondence: veronika.hahn@inp-greifswald.de; Tel.: +49-3834-554-3872
}

Received: 5 August 2020; Accepted: 2 September 2020; Published: 3 September 2020

\begin{abstract}
The nursing of patients with wounds is an essential part of medical healthcare. In this context, cold atmospheric-pressure plasma sources can be applied for skin decontamination and stimulation of wound healing. One of these plasma devices is the commercially available kINPen ${ }^{\circledR}$ MED (neoplas tools $\mathrm{GmbH}$ ), a cold atmospheric-pressure plasma jet which is approved as a medical device, class-IIa. For the plasma treatment, a sterile disposable spacer is recommended to ensure a constant and effective distance between plasma and skin. The disadvantage of this spacer is its form and size which means that the effective axis/area is not visible for the attending doctor or qualified personnel and consequently it is a more or less intuitive treatment. In addition, the suggested perpendicular treatment is not applicable for the attending specialist due to lack of space or patient/wound positioning. A concept of a sensory unit was developed to measure the treatment distance and to visualize the effective treatment area for different angles. To determine the effective area for the plasma treatment, some exemplary methods were performed. Thus, the antimicrobial (Staphylococcus aureus DSM799/ATCC6538) efficacy, reactive oxygen species (ROS) distribution and (vacuum) ultraviolet ((V)UV) irradiation were determined depending on the treatment angle. Finally, a simplified first approach to visualize the effective treatment area at an optimal distance was designed and constructed to train attending specialists for optimal wound area coverage.
\end{abstract}

Keywords: chronic wound; kINPen; treatment control; multidrug-resistant microorganisms; diabetic foot

\section{Introduction}

The The kINPen ${ }^{\circledR}$ MED (neoplas tools $\mathrm{GmbH}$, Greifswald, Germany) is a cold atmospheric-pressure plasma (CAP) jet which is CE-certified as a medical device, class IIa $[1,2]$. The generated CAP is an excited and conductive gas state with low temperature $\left(<40{ }^{\circ} \mathrm{C}\right)$ which emits electromagnetic radiation, like ultraviolet, visible and infrared radiation, and other 
electromagnetic fields and generates charged particles and reactive species [3-5]. The most important species-in particular for the antimicrobial efficacy of CAP - are reactive oxygen (ROS) and nitrogen species (RNS) [6,7]. These species include atomic oxygen $(\mathrm{O})$, ozone $\left(\mathrm{O}_{3}\right)$, hydrogen peroxide $\left(\mathrm{H}_{2} \mathrm{O}_{2}\right)$, nitrite $\left(\mathrm{NO}_{2}{ }^{-}\right)$, nitrate $\left(\mathrm{NO}_{3}{ }^{-}\right)$, nitric oxide $\left(\mathrm{NO}^{\bullet}\right)$, hydroxyl radicals $(\mathrm{HO})^{\bullet}$ ), superoxide anion radicals $\left(\mathrm{O}_{2}{ }^{\bullet-}\right)$ and singlet oxygen $\left({ }^{1} \mathrm{O}_{2}\right)[5,8,9]$. The kINPen ${ }^{\circledR}$ is able to inactivate clinically relevant microorganisms which were isolated from patients with acute or chronic wounds, such as Staphylococcus aureus, Klebsiella pneumonia or Proteus mirabilis $[10,11]$. However, the kINPen ${ }^{\circledR}$ has not only an antimicrobial efficacy, it also stimulates the cell proliferation and migration and thereby tissue regeneration in the course of wound healing. The antiseptic efficacy and wound healing support on human or animal skin was confirmed for the $\mathrm{kINPen}^{\circledR}$ in clinical studies and animal trials $([1,12-19]$, for reviews please refer to [20,21]).

The intensity of the treatment with the kINPen ${ }^{\circledR}$ MED is controlled by the treatment time. Thus, $30-60 \mathrm{~s} / \mathrm{cm}^{2}$ is the recommended treatment condition and the procedure is repeated every few days until the desired effect is achieved. The plasma treatment is currently realized by a sterile disposable spacer which mechanically guarantees a pre-defined distance of at least $7 \mathrm{~mm}$ between the skin surface and nozzle. This spacer is made of biocompatible plastic and can easily be placed on the tip of the pen-shaped handset of the $\mathrm{kINPen}{ }^{\circledR}$ MED (Figure 1). However, the distance defined by the spacer and a perpendicular treatment with the $\mathrm{kINPen}{ }^{\circledR}$ MED are recommendations $[2,22]$ the attending doctor or qualified personnel cannot comply with absolutely due to lack of space or patient/wound positioning, as well as sensitive wound tolerance levels. Furthermore, the effective area of the kINPen ${ }^{\circledR}$ MED cannot be seen with the naked eye.

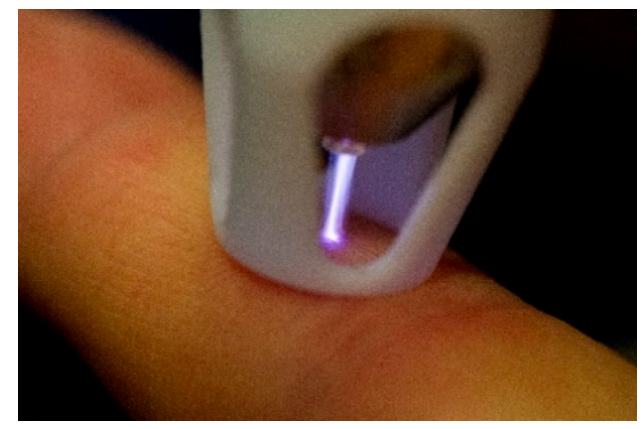

Figure 1. The $\operatorname{kINPen}^{\circledR}$ MED with spacer on skin.

Thus, a concept was developed for a contact-free spacer to visualize the effective treatment area and to detect the treatment distance. In order to visualize the effective area, the relevant wound pathogen Staphylococcus aureus DSM 799/ATCC 6538 (DSM-German Collection of Microorganisms and Cell Cultures, ATCC-American Type Culture Collection) was used to determine the zone of antibacterial efficacy. In addition, the area of ROS formation and the impact of (vacuum) ultraviolet $((\mathrm{V}) \mathrm{UV})$ irradiation were determined. The effective area was analyzed depending on the incidence angle, which was the prerequisite for the design of the novel concept. Thus, the introduced construction enables a contactless plasma treatment with an unobstructed, illuminated view over the effective area and a free energy exchange with the surrounding air.

\section{Materials and Methods}

\subsection{Plasma Device}

A test device identical to the commercially available medical plasma device kINPen ${ }^{\circledR}$ MED (neoplas tools GmbH, Greifswald, Germany) called kINPen ${ }^{\circledR}$ MED- $\beta$ was used. The kINPen ${ }^{\circledR}$ MED consists of an operating device and a handset which is supplied via a combined line for gas, voltage and a protective earth conductor. A high-frequency generator with a frequency of $1 \mathrm{MHz}$ is applied 
to a stainless steel electrode in needle geometry, which is situated inside a ceramic capillary. On this electrode, a high electrical voltage of $2-3 \mathrm{kV}$ is generated [3,5]. The counter electrode is a ring electrode, which distally surrounds the capillary. The feed gas of argon flows with $5 \mathrm{slm}$ through the capillary. The plasma ignition is bursted with a frequency of $2.5 \mathrm{kHz}$ and a $50 \%$ duty circle. For the treatment of surfaces such as skin, a distance of $7 \mathrm{~mm}$ to $10 \mathrm{~mm}$ is recommended [3,22].

\subsection{Experimental Setup}

For the variation of the treatment distance and incidence angle, an experimental setup was designed by Autodesk Inventor Professional 2017 (Autodesk Inc., San Rafael, CA, USA). For the detection of ROS, requiring $55 \mathrm{~mm}$ plates, the setup was printed by the 3D printer Ultimaker2+ extended (Ultimaker, Utrecht, the Netherlands) and for the microbiological examinations with $84 \mathrm{~mm}$ plates, the 3D printer Prusa (Prusa Research s.r.o., Prague, Czech Republic) was used.

The respective setup consisted of an optical rack with a semi-circular rail which possessed notches on one side in $5^{\circ}$ steps (Figure 2). A carriage can be moved on this rail, which contained the kINPen ${ }^{\circledR}$ MED- $\beta$. The kINPen ${ }^{\circledR}$ Med- $\beta$ was always tilted in the same direction from the top to the left (Figure $2 \mathrm{a}, \mathrm{c}, 0^{\circ}$ to $50^{\circ}$ (and up to $60^{\circ}$ for $(\mathrm{V}) \mathrm{UV}$ determination without plates)). The distance from the nozzle to the surface of the sample was $8.5 \mathrm{~mm}$. A height-adjustable sample holder was also part of the optical rack to ensure an easy exchange of samples.

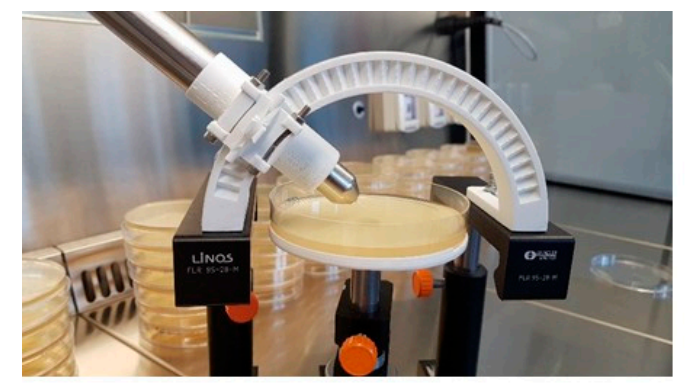

(a)

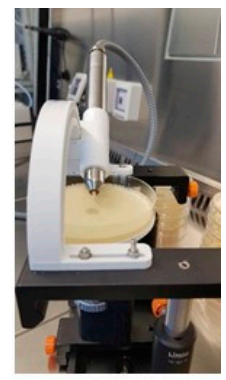

(b)

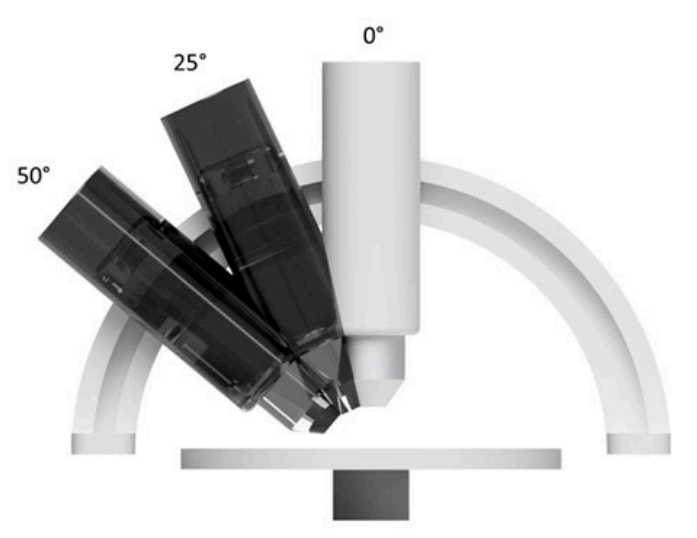

(c)

Figure 2. Experimental setup for the determination of the plasma effective area; (a) photo: direction for the tilted treatment (incidence angle: from top to left), (b) sideview, (c) scheme.

\subsection{Starch-Potassium Iodide Test}

In order to determine the plasma effective zone, ROS were chosen as the most important plasma-generated effective species. As a detection reagent, a starch-potassium iodide mixture was used. The principle is based on the oxidation of iodide ions to iodine, which is described in particular for the detection of ozone [23,24] but also for hydrogen peroxide [25] or nitrous acid [26]. Thus, the iodine 
and the iodide species can react to polyiodide anions, which form complexes with the amylose helices as part of the starch. This resulted in a color change from white/yellow to blue-brown/black [27].

For the preparation of the plates, $100 \mathrm{~mL}$ water, $2 \mathrm{~g}$ starch and $2.5 \mathrm{~g}$ agar-agar were boiled to dissolve the agar. After the solution cooled down to approximately $40{ }^{\circ} \mathrm{C}, 2 \mathrm{~g}$ potassium iodide were added. The solution was portioned into $5 \mathrm{~mL}$ per plate (diameter: $55 \mathrm{~mm}$ ). All chemicals were purchased from Carl Roth GmbH \& Co. KG, Karlsruhe, Germany.

The starch-potassium iodide plates were treated with kINPen ${ }^{\circledR}$ MED- $\beta$ using $45 \mathrm{~s}$ treatment time and different incidence angles of $0^{\circ}, 25^{\circ}, 50^{\circ}$, whereby $0^{\circ}$ corresponded to a perpendicular treatment. The distance between the nozzle and agar surface was $8.5 \mathrm{~mm}$. Afterwards, the samples were photographed (Canon EOS 7D, Tokyo, Japan; lens-object distance: $47.3 \mathrm{~cm}$, exposure time: $0.033 \mathrm{~s}$, aperture: 9.5, ISO 125 setting without white balance; 50 pixels $=1 \mathrm{~mm}$ ) and analyzed by Matlab (Matlab R2012a, MathWorks ${ }^{\circledR}$, Natick, MA, USA).

\subsection{Ultraviolet (UV) and Vacuum Ultraviolet (VUV) Irradiation Profile Test}

For the analysis of the plasma effective area caused by UV or VUV irradiation on a sample surface, a detection based on fluorescent excitation with distinct wavelength sensitivity was established. For UV irradiation detection, a $2 \mathrm{~mm}$ quartz substrate was sedimented without binder with a fluorescent dye $\left(\mathrm{BaMgAl}_{10} \mathrm{O}_{17}: \mathrm{Eu}^{2+}\right.$ or short $\left.\mathrm{BAM}: \mathrm{Eu}\right)$. A further quartz plate shielded the fluorescent dye from the mechanical gas flow. The spectral sensitivity of the dye in combination with the covering quartz plate was in the range of $200 \mathrm{~nm}$ to $370 \mathrm{~nm}$, hence allowing the $\mathrm{OH}$ (at approximately $310 \mathrm{~nm}$ ) and $\mathrm{N}_{2}$ (spectral range from $300 \mathrm{~nm}$ up to $410 \mathrm{~nm}$ ) irradiation to pass through [4,28]. For VUV irradiation detection, a glass plate was sedimented without binder with a different fluorescent dye $\left(\mathrm{Zn}_{2} \mathrm{SiO}_{4}: \mathrm{Mn}\right)$. $\mathrm{A} \mathrm{MgF}_{2}$ window was placed on top of the fluorescent dye to shield the dye from the gas flow and allow for VUV light transmission. In this combination, a VUV sensitivity in the range of $115 \mathrm{~nm}$ to $275 \mathrm{~nm}$ could be achieved. Hence, the emission of the 2 nd continuum of the argon excimer (115 $\mathrm{nm}$ to $140 \mathrm{~nm})$, atomic oxygen $(130 \mathrm{~nm})$ and atomic nitrogen $(120 \mathrm{~nm}, 150 \mathrm{~nm}$ and $175 \mathrm{~nm})$ in the VUV could be detected [28], as well as the third argon excimer continuum from $170 \mathrm{~nm}$ to $220 \mathrm{~nm}$. The samples were photographed (Canon EOS 7D, Tokyo, Japan; lens-object distance: $47.3 \mathrm{~cm}$, exposure time for UV: $3 \mathrm{~s}$ and for VUV: $3 \mathrm{~s}$, aperture: 9.5, ISO 125 setting without white balance; 50 pixels $=1 \mathrm{~mm}$ ) and analyzed by Matlab (Matlab R2012a, MathWorks ${ }^{\circledR}$, Natick, MA, USA). In sum, approximately 1.5 million ignitions were accumulated in one acquisition.

\subsection{Inhibition Zone Assay}

The bacterium Staphylococcus aureus DSM 799/ATCC 6538 (DSM-German Collection of Microorganisms and Cell Cultures, ATCC-American Type Culture Collection) was cultured on soybean casein digest agar (Carl Roth GmbH \& Co. KG, Karlsruhe, Germany). After an incubation of $24 \mathrm{~h}$ at $37^{\circ} \mathrm{C}$, the agar plates were stored at $8{ }^{\circ} \mathrm{C}$.

To determine the antimicrobial effect of plasma, experiments were carried out according to the German pre-standard DIN SPEC 91315:2014-06 [2,29].

S. aureus was cultured in $20 \mathrm{~mL}$ soybean casein digest broth (Carl Roth $\mathrm{GmbH} \& \mathrm{Co}$. KG, Karlsruhe, Germany). After an incubation time of $24 \mathrm{~h}$ at $37^{\circ} \mathrm{C}, 10 \mathrm{~mL}$ of the culture were centrifuged ( $4700 \mathrm{rpm}$; Heraeus Multifuge 1S, Thermo Fisher Scientific, Schwerte, Germany) for $5 \mathrm{~min}$. The supernatant was discarded and the cells were suspended in $10 \mathrm{~mL}$ saline solution $(0.85 \%)$.

The bacterial suspension was adjusted to a total viable count of $10^{6} \mathrm{cfu} / \mathrm{mL}$. Afterwards, $100 \mu \mathrm{l}$ of the bacterial solution were spread on a plate (diameter: $84 \mathrm{~mm}$ ) with soybean casein digest agar. Localized spot-like CAP treatments by kINPen ${ }^{\circledR}$ MED- $\beta$ with different angles $\left(0^{\circ}, 25^{\circ}, 50^{\circ}\right)$ for $30 \mathrm{~s}$, $45 \mathrm{~s}$ and $60 \mathrm{~s}$, respectively, were carried out on the inoculated agar plates $(n=6)$. The distance between the nozzle and the surface of the wet solid medium was $8.5 \mathrm{~mm}$. The agar plates were incubated for $24 \mathrm{~h}$ at $37^{\circ} \mathrm{C}$. The plates with growth inhibition zones (defined as areas without visible growth of $S$. aureus; named in accordance with agar disc diffusion assay) were photographed (Canon EOS 
7D, Tokyo, Japan; lens-object distance: $47.3 \mathrm{~cm}$, exposure time: $0.033 \mathrm{~s}$, aperture: 9.5, ISO 125 setting without white balance; 32 pixels $=1 \mathrm{~mm}$ ) and analyzed by Matlab.

\subsection{Evaluation of Effective Area}

The experimental data of the starch-potassium iodide test, the (V)UV determination and the microbiological assay were analyzed by Matlab programs. The basic program was adjusted according to the available signal to noise ratio to enable a correlation between the determination of reactive species and the (V)UV irradiance area which were both suspected to be responsible for the biological efficacy. The basic principle of the program is a transformation into grayscale, a substraction of background noise and finally a definition of primary, secondary and peripheral zones based on intensity levels. Every zone is defined by setting thresholds above the background signal. The determination of the inhibition zone area was performed manually by counting the pixels in two dimensions, rescaling with the placed scale on each picture and calculating the area of an ellipse with both dimensions.

\section{Results}

At first, a concept of a sensory unit was developed which comprised the measurement of the treatment distance and the visualization of the effective treatment area. Afterwards, the visualized effective area was determined by different methods. For this, the ROS formation, the (V)UV irradiation and the antimicrobial efficacy were measured. Thus, a correlation of the visualized area and the effective area was possible.

\subsection{Concept of Sensors and Illumination}

A laser sensor with safety class I was chosen to enable a precise distance measurement at one point and to achieve an unobstructed view over the treated area. Despite the recommended perpendicular treatment of the skin, in reality, the attending specialist mostly applies the kINPen ${ }^{\circledR}$ MED- $\beta$ with an incidence angle of $25^{\circ}$ to $40^{\circ}$. This results in an elliptical (comet-like) effective zone and in an elliptical reflection area of the sensor signal (Figure 3).

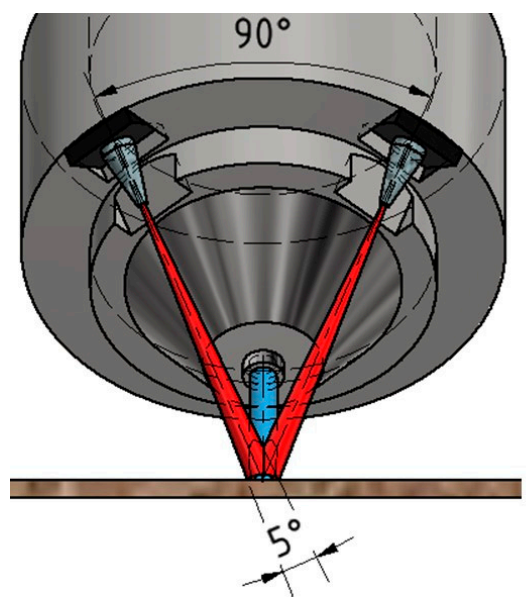

(a)

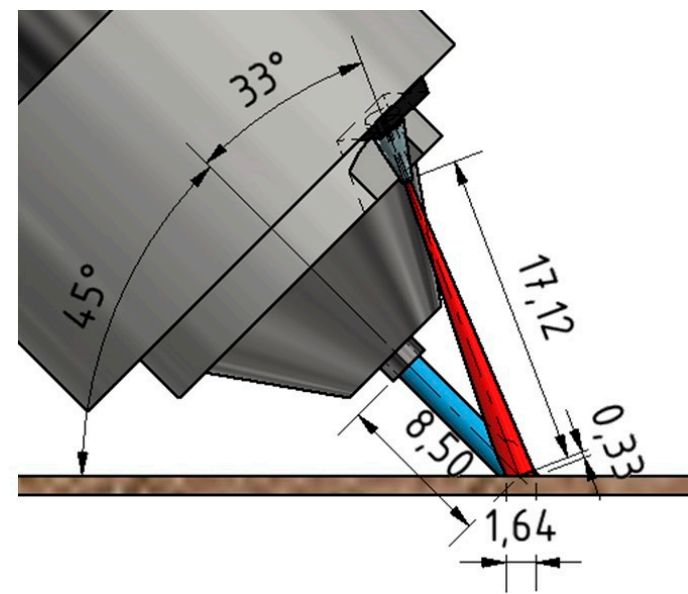

(b)

Figure 3. Concept of sensors: (a) front view, (b) side view; blue: visible plasma effluent, red: laser beams.

Two laser sensors (VL6180X) are distributed around the kINPen ${ }^{\circledR}$ MED- $\beta$. The laser proximity sensor works based on absolute time of flight measurement. The time required for the signal to be detected after transmission and reflection is proportional to the distance the signal travels. The chosen sensor possesses a cross talk elimination option and ambient light detection. In this way, it can detect the signal precisely even at short distances and independent of the reflectance and color of the reflecting 
surface. The sensors are aligned directly with the effluent at a distance of $7 \mathrm{~mm}$ to $10 \mathrm{~mm}$ (on average $8.5 \mathrm{~mm}$ ) to ensure the maximum efficacy when the kINPen ${ }^{\circledR}$ MED- $\beta$ is tilted, but also in case of a vertical application. In order to further minimize the signal area, an aperture is placed in front of the sensor. This ensures that the sensor area lies directly on the effluent and scarcely more area is detected than the visual effluent contact area of the kINPen ${ }^{\circledR}$ MED- $\beta$. This eliminates errors caused by unevenness and mistakes through tilting. It has to be mentioned that the conceivable laser sensor VL6180X works with a wavelength of $850 \mathrm{~nm}$. The plasma generated by kINPen ${ }^{\circledR}$ MED- $\beta$ and argon as a feed gas also emits light of this wavelength, which may result in an incorrect distance measurement. In case this could be a problem under application-oriented conditions, the focus of the sensors can be shifted, albeit the possibility of errors due to unevenness may increase again. In addition, it has to be ensured that the device is not tilted in such a way that the sensors lie on the bottom side. Thus, the upper side should therefore be clearly marked or four sensors should be used with a automatic recognition of the sensor position. It is known that the effective area of the kINPen ${ }^{\circledR}$ MED- $\beta$ is larger than the visible effluent $[2,30]$. Thus, this area has to be visualized for the attending specialist. This illumination should be visible under application-oriented light conditions and should not influence the functionality of the kINPen ${ }^{\circledR}$ MED- $\beta$. Thus, several LEDs can be arranged symmetrically around the kINPen ${ }^{\circledR}$ MED- $\beta$, illuminating a large part of the surface (Figure 4). The LEDs have to be positioned in such a way that the beam geometries of the illumination cones and of the efficacy cones are adjacent to each other. In addition, a ring aperture should be placed in front of the LEDs, which would only allow a narrow gap of light to pass through. The gap forms a circle that encloses the effective area.

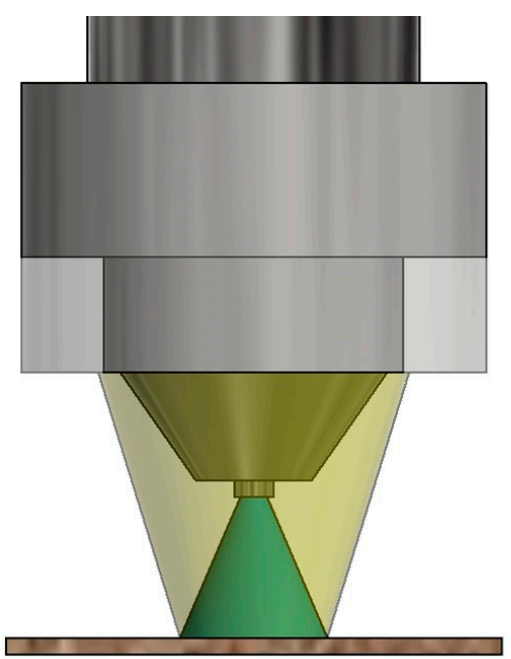

(a)

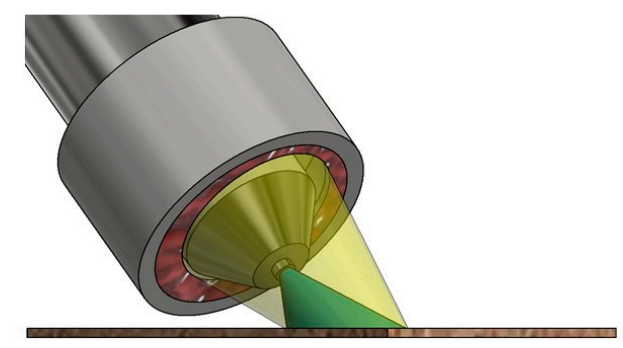

(c)

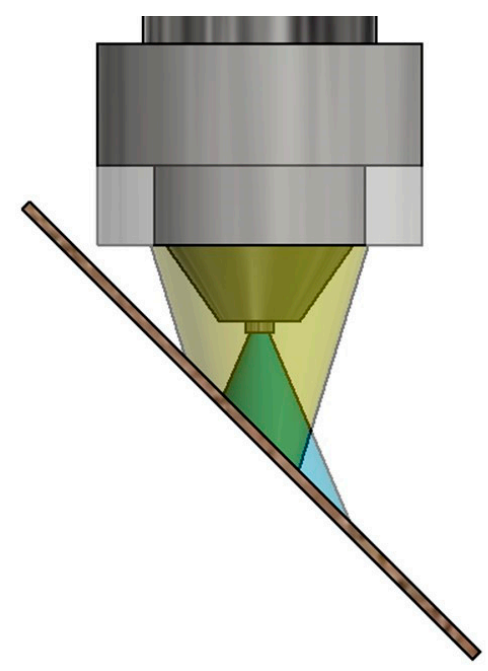

(b)

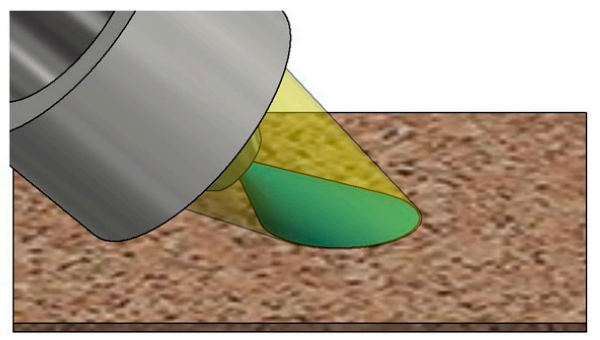

(d)

Figure 4. Concept of visualization; Illumination of treatment area using circular aperture for fixed incidence angle (aperture replaceable); (a) circular aperture for perpendicular $\left(0^{\circ}\right)$ and (b) tilted application, (c,d) including different perspectives using tilted device; green: estimated effective plasma zone, yellow: LED-illuminated zone. 
To confirm the efficacy of the introduced concept, some exemplary test methods were used to determine the influence of the incidence angle on the ROS distribution, (V)UV irradiation and antimicrobial property of the plasma source. This approach may be a possibility for the determination of the effective area dependent on a novel developed or re-adjusted concept for the tip of the handset of the kINPen ${ }^{\circledR}$ MED.

\subsection{Determination of the Effective Treatment Area}

The plasma treatment of agar plates inoculated with S. aureus DSM 799/ATCC 6538 as a test microorganism resulted in the formation of inhibition zones (defined as areas without visible growth). The shape of the zone was circular for vertical treatment and became increasingly elliptical with increased tilting (Figure 5).

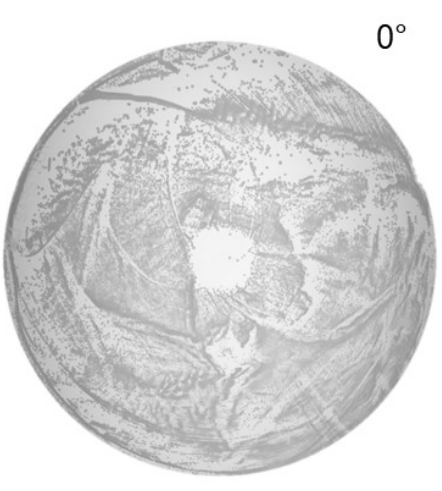

(a)

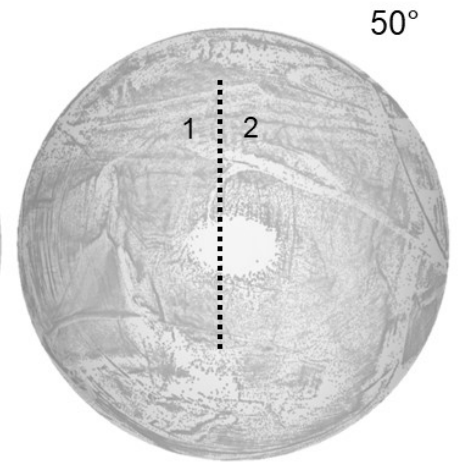

(b)

Figure 5. Effective treatment area of $\mathrm{kINPen}{ }^{\circledR}$ MED- $\beta$ visualized by inhibition zone assay at $8.5 \mathrm{~mm}$ distance after $45 \mathrm{~s}$ plasma treatment for (a) perpendicular treatment and (b) an incidence angle of $50^{\circ}$ (side 1: inclination of the kINPen ${ }^{\circledR}$ MED- $\beta$ as shown in Figure $2 c$, side 2: area with plasma plume propagation); test bacterium: Staphylococcus aureus DSM 799/ATCC 6538).

The width and length of the zones decreased at least slightly (by 7-14\%) and increased (by 30-36\%), respectively, with rising incidence angle (Figure $6 a, b)$. The total effective area increased with rising treatment time and tilting (Figure $6 \mathrm{c}$ ). Thus, the effective area for a $50^{\circ}$ tilt was $25 \%$ bigger than for the vertical treatment for $45 \mathrm{~s}$.

For the ROS, depending on the applied treatment axis, a circular or elliptic shape of the effective area was determined (Figure $7 \mathrm{a}, \mathrm{b}$ ). The plasma treatment of the starch-potassium iodide plates resulted in three effective zones which can be separated from the center to the outside into primary, secondary and peripheral zones. The primary zone was the area where the visible effluent had direct contact with the starch-potassium iodide plates. This zone was characterized by a dark brown to deep black spot. The secondary zone had a brownish color and was formed directly around the primary zone. The peripheral zone was a diffuse dark yellow area on the outside. These different zones can be separated by a Matlab program resulting in a false color photo with the primary zone in green, the secondary zone in blue and the peripheral zone in red (Figure $7 c, d)$.

Depending on the applied treatment axis, the zones were circular or elliptic with a comet-like shape. If the samples were treated vertically, a circular effective area was obtained which was characterized by all three zones (Figure 7a,c). With increasing tilting of the kINPen ${ }^{\circledR}$ MED- $\beta$, the shape of the effective zones became increasingly comet-like with an intense center spot and an expanding tail (Figure $7 \mathrm{~b}, \mathrm{~d}$ ).

The correlation between the antimicrobial efficacy and the ROS determination (Figure 8) showed that the width between the secondary and the peripheral zone and the length of the inhibition zone were similar to the peripheral zone of the ROS formation (for $45 \mathrm{~s}$ and $0^{\circ}, 25^{\circ}, 50^{\circ}$ ). 


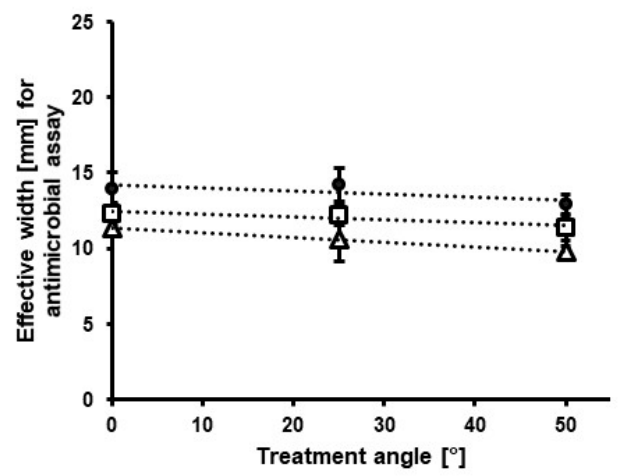

(a)

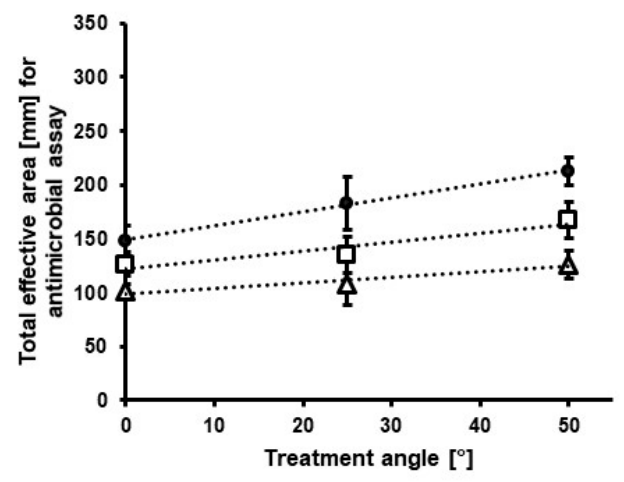

(c)

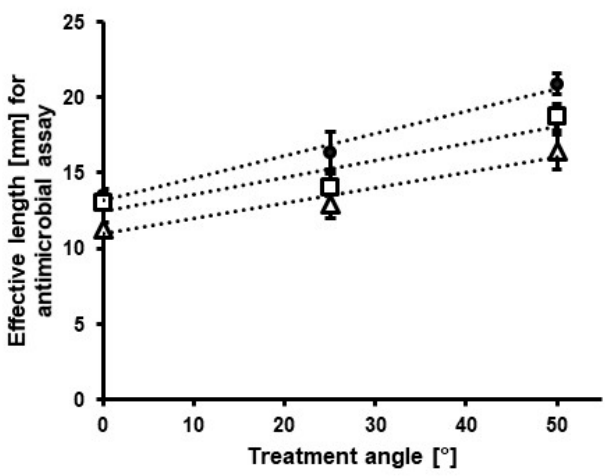

(b)

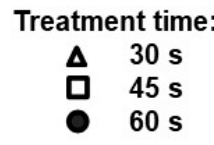

Figure 6. Alteration of (a) width, (b) length and (c) total area depending on incidence angle $\left(0^{\circ}, 25^{\circ}, 50^{\circ}\right)$ and plasma treatment time (30, 45 and $60 \mathrm{~s}$ ) of inoculated agar plates (Staphylococcus aureus DSM 799/ATCC 6538) with kINPen ${ }^{\circledR}$ MED- $\beta(M \pm S D, n=6)$. After the visualization of the biological effective area for the kINPen ${ }^{\circledR}$ MED- $\beta$, the question arose if this shape-in particular, the elliptical shape-of the inhibition zone during tilted treatment can be correlated with a non-biological parameter (Figure 5b). Therefore, the reactive oxygen species (ROS) and (vacuum) ultraviolet (V)UV distribution on the treated surface was analyzed with regard to the influence of the incidence angle on the shape of the effective area on a treated surface.

The total area of the inhibition zones (S. aureus) increased (Figure 6c) whereas ROS decreased slightly by $9 \%$ with rising incidence angle (Figure 9). Thus, the total area of the inhibition zone in the antimicrobial assay for $50^{\circ}$ was $16 \%$ larger than that of the ROS analysis.

The data obtained from VUV irradiation tests for different treatment angles showed that the excited fluorescent dye for VUV emitted green light in a circular shape for a vertical treatment. The excited fluorescent dye for VUV emitted green light in a circular shape for a vertical treatment (Figure 10a). In the case of a tilted treatment despite central positioning of the plasma jet, the impact point of the radiation shifted slightly to the right due to the additional shielding window on top of the dye (Figure 10). It was expected that the plasma would propagate slightly on top of the shielding window and hence the impact point would move further. Thus, the formed shape of the excited area is rather an inverse comet compared to the area for ROS. In the case of UV, the fluorescent dye emitted blue light (Figure 10b) in similar shapes to the VUV tests (Figure 10a), while the overall area was much larger for the UV test. Three zones could also be separated from the center to the outside into primary, secondary and peripheral zones (Figure 10c,d). 

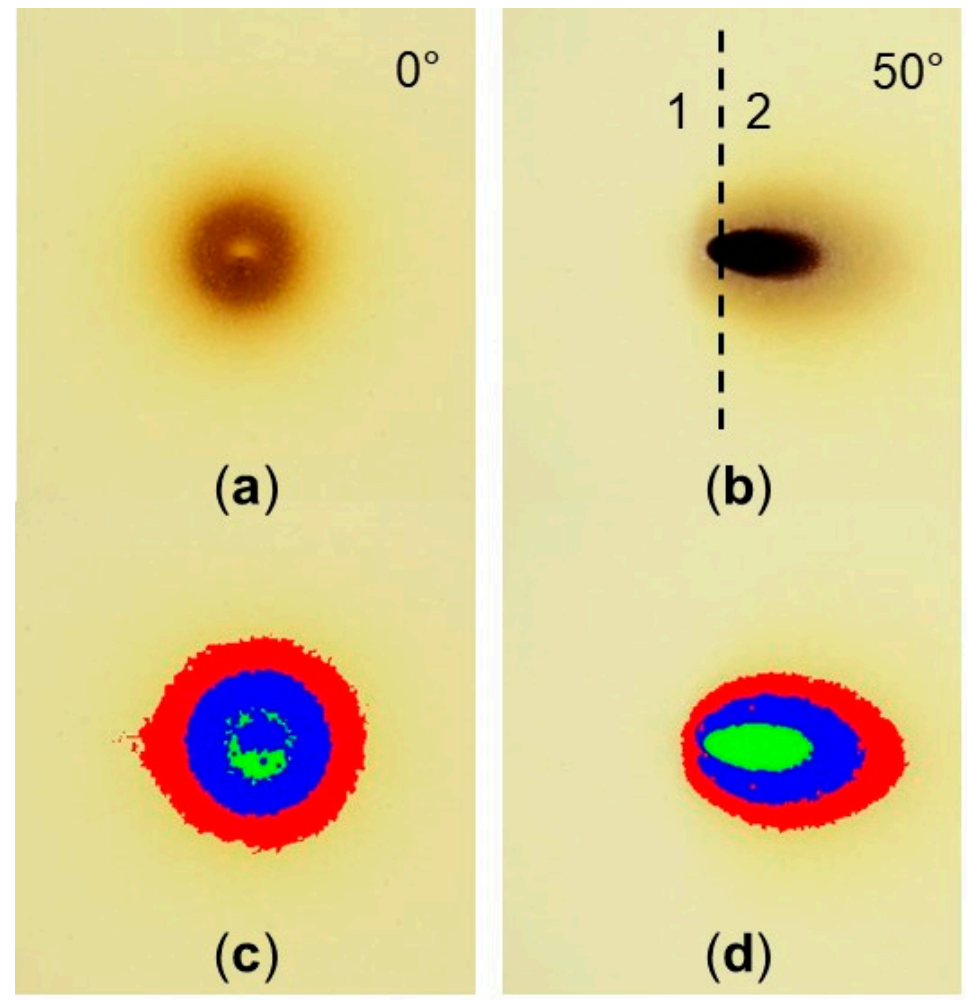

Figure 7. Effective treatment area of kINPen ${ }^{\circledR}$ MED- $\beta$ visualized by starch-potassium iodide plates at $8.5 \mathrm{~mm}$ distance after $45 \mathrm{~s}$ plasma treatment for (a) perpendicular treatment and (b) an incidence angle of $50^{\circ}$ (side 1: inclination of the kINPen ${ }^{\circledR}$ MED- $\beta$ as shown in Figure 2c, side 2: area with plasma plume propagation) and (c,d) analyzed according to primary (green), secondary (blue) and peripheral (red) zones.

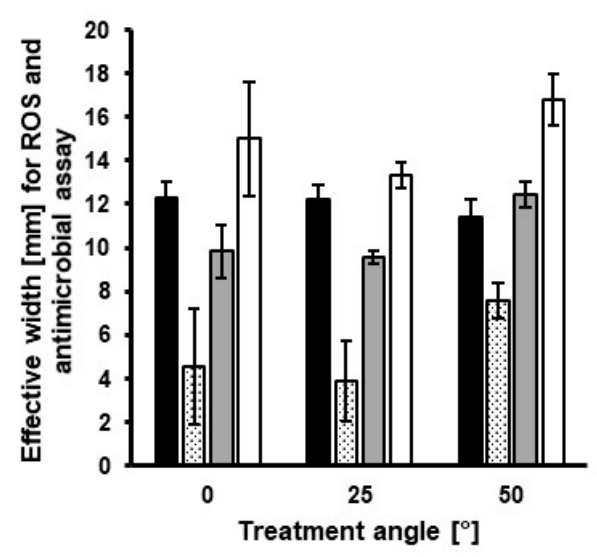

(a)

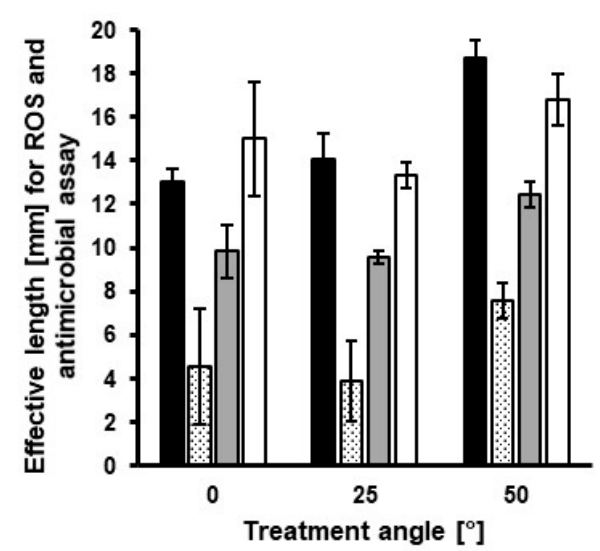

(b)

inhibition zone (antimicrobial assay)

primary $\square$ secondary $\square$ peripheral zone (ROS determination)

Figure 8. Effective (a) width and (b) length of the inhibition zones in the antimicrobial assay (Staphylococcus aureus DSM 799/ATCC 6538, M $\pm \mathrm{SD}, n=6$ ) and the ROS determination $(\mathrm{M} \pm \mathrm{SD}, n=3$ ) of primary, secondary and peripheral zones depending on incidence angle $\left(0^{\circ}, 25^{\circ}, 50^{\circ}\right)$ after $45 \mathrm{~s}$ treatment with kINPen ${ }^{\circledR}$ MED- $\beta$. 


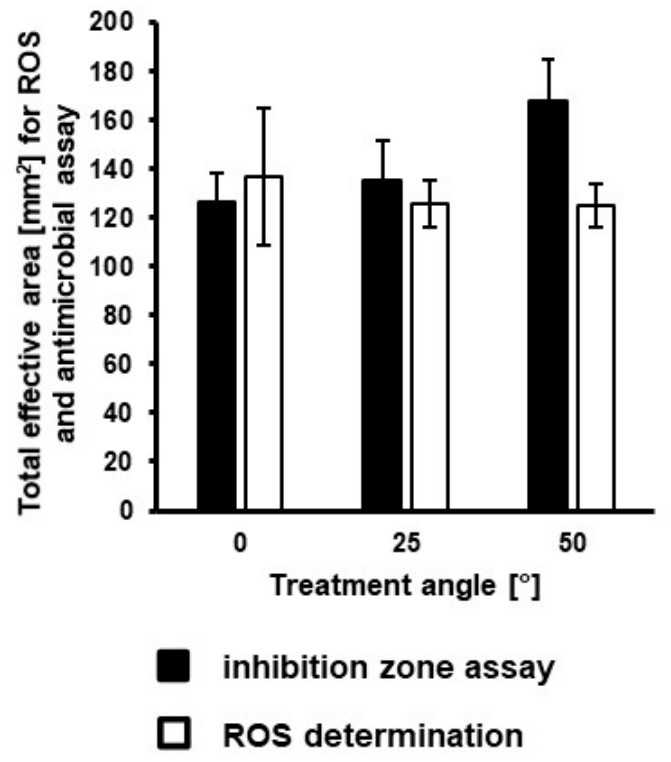

Figure 9. Total effective area depending on incidence angle $\left(0^{\circ}, 25^{\circ}, 50^{\circ}\right)$ after $45 \mathrm{~s}$ treatment with kINPen ${ }^{\circledR}$ MED- $\beta$ for the inhibition zone assay (Staphylococcus aureus DSM 799/ATCC 6538, M \pm SD, $n=6)$ and ROS determination (M $\pm \mathrm{SD}, n=3)$.

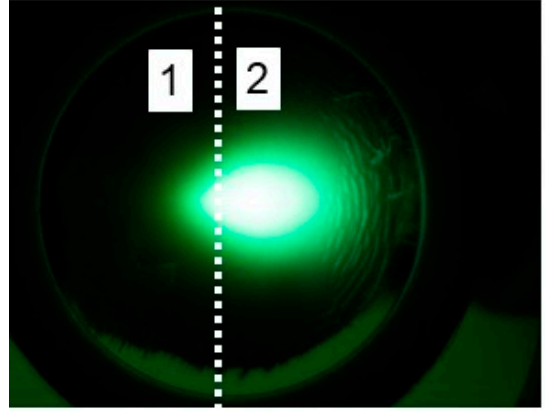

(a)

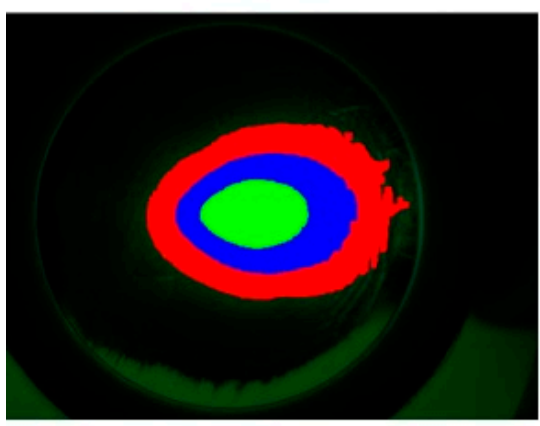

(c)

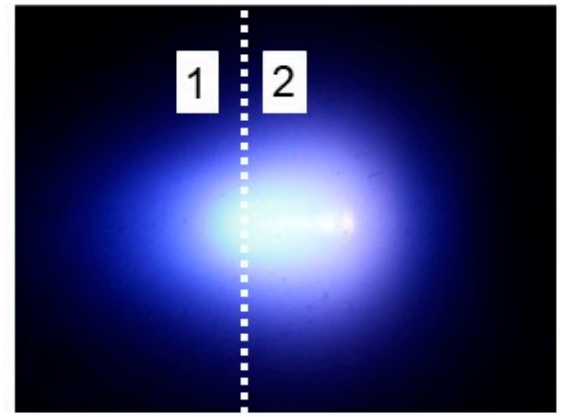

(b)

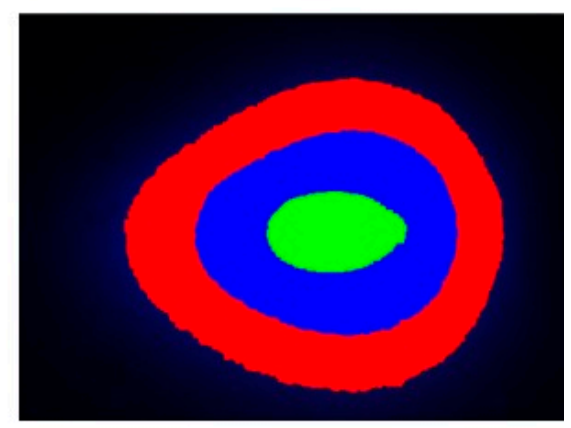

(d)

Figure 10. (a) VUV and (b) UV irradiation profile for an incidence angle of $60^{\circ}$ (side 1: inclination of the kINPen ${ }^{\circledR}$ MED- $\beta$ as shown in Figure 2c, side 2: area with plasma plume propagation) and (c,d) analyzed according to primary (green), secondary (blue) and peripheral (red) zones.

The width of the effective zones increased by $23 \%$ in the case of VUV and remained stable for UV, whereas the length remained stable for VUV and decreased by $19 \%$ for UV with a rising incidence angle of the kINPen ${ }^{\circledR}$ MED- $\beta$ (Figure 11a,b). The total area of VUV was smaller compared to UV because of the strong absorption within the ambient air outside the argon gas-containing plasma 
effluent (Figure 11c). Additionally, the total area of the UV radiation zone decreased by $21 \%$, whereas the size of the VUV zone was independent of the incidence angle.

The total area of the inhibition zones (S. aureus) increased (Figure 6c), whereas UV slightly decreased and VUV remained stable with rising incidence angle (Figure 12).

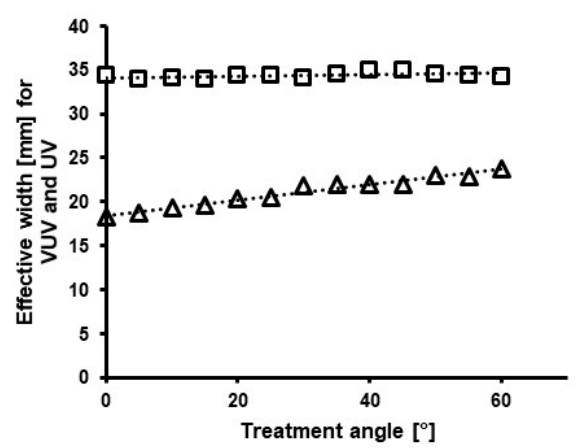

(a)

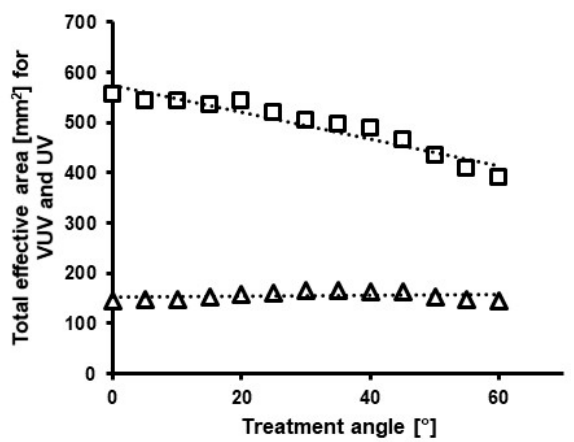

(c)

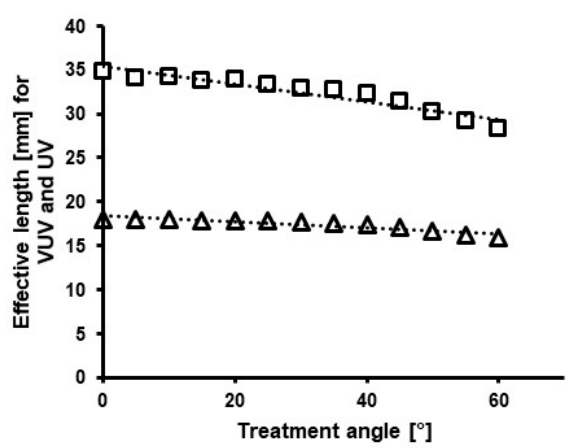

(b)
Radiation:

$\Delta \quad$ VUV

Figure 11. Alteration of (a) width, (b) length and (c) total area of VUV and UV irradiation caused by kINPen ${ }^{\circledR}$ MED- $\beta$ after perpendicular $\left(0^{\circ}\right)$ and tilted $\left(5-60^{\circ}\right)$ application visualized by fluorescence dyes.

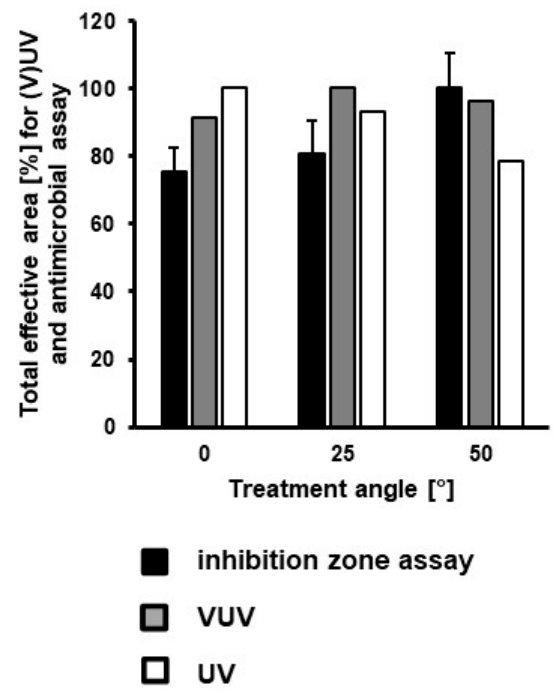

Figure 12. Total effective area depending on incidence angle $\left(0^{\circ}, 25^{\circ}, 50^{\circ}\right)$ with $\mathrm{kINPen}{ }^{\circledR}$ MED- $\beta$ for the inhibition zone assay (after 45 s treatment; Staphylococcus aureus DSM 799/ATCC 6538, M \pm SD, $n=6)$ as well as VUV and UV. 


\section{Discussion}

The aim of this study was to design a concept for a contact-free spacer to visualize the effective treatment area of the cold atmospheric-pressure plasma jet kINPen MED and to detect and control the treatment distance. This should enable a contactless plasma treatment with an unobstructed, illuminated view over the effective area and free energy exchange with the surrounding air.

In order to realize the visualization of an effective treatment area, a variety of measurements were performed to verify the assumption of an impact of the treatment angle on the effective area. It was confirmed that the effective area was strongly dependent on the treatment angle. Thus, a sensor arrangement that visualizes the effective area has to consider the treatment angle. Furthermore, the individual effective areas of ROS, (V)UV and inhibition zone assays were not congruent. This indicated specific distribution properties.

The plasma effective zone was analyzed by three test settings, the starch-potassium iodide test, the (V)UV determination and the inhibition zone assay. In the latter case S. aureus (DSM 799/ATCC 6538) was used as test microorganism. The starch-potassium iodide test was used to provide an alternative fast and easy method for the determination of the plasma effective zone via ROS surface contact distribution without the utilization of biological samples, such as microorganisms.

The biological effective area for S. aureus was larger with increasing incidence angle. Thus, it is necessary to know and visualize the effective area to ensure an optimal treatment of the targeted surface, e.g., a wound. The antimicrobial and ROS analyses resulted in circular zones when the kINPen ${ }^{\circledR}$ MED- $\beta$ was applied vertically and in elliptical/comet-like zones after tilting of the device. Under the chosen treatment conditions $\left(45 \mathrm{~s}\right.$ and $0^{\circ}, 25^{\circ}, 50^{\circ}$ ), the inhibition zone was between the secondary and the peripheral zone of the ROS formation regarding width and similar to the peripheral zone for the length of ROS formation. However, the total area of the inhibition zone increased, whereas ROS decreased (at least by $9 \%$ ) with rising treatment angle. This supports the assumption that ROS is one main factor for antimicrobial efficacy, but not the only one.

This may also be explained by the selectivity of the starch-potassium iodide plates. In this test, the proof of plasma efficacy was shown by the reactivity of the ROS with the surface of the starch-potassium iodide plates using different angles of the plasma source. The maximum ROS density was measured directly in the visible effluent [6,31]. In this area, a violet effluent was formed around the blue argon part, whereby the effluent consisted mainly of an ionized ROS environment [32,33]. Additionally, it is well known that a low leakage current occurs at the contact area of the effluent with the starch-potassium iodide plates [34]. This might result in the formation of polyiodide and thereby in a dark brown to black discoloration of the primary zone that is not caused solely by a ROS-based oxidation process. The ROS formed around the plasma effluent should be transported with the argon gas flow to the surface and spread according to the flow direction, which leads to a comet-shaped effective area. The secondary zone is supposed to be the result of less intense short-lived ROS. The density of the ROS decreased with increasing distance from the plasma zone. This is caused by reactions with ambient air, diffusion, turbulent gas flows and other interactions with the environment while being countered by argon metastable recombination processes releasing energy and inducing a complex plasma chemistry even in the afterglow [35]. We hypothesized that this resulted in an extensive peripheral zone. A recent study also showed that an increased incidence angle using a helium-driven discharge at short treatment distance improved the water contact angle and showed a rather homogenous and wide spread of ROS compared to a vertical treatment [34].

Another factor which was determined to characterize the effective area is the (V)UV irradiation. The UV irradiation, in accordance with ROS, decreased (from $0^{\circ}$ to $50^{\circ}$ ) by $21 \%$ and $9 \%$, respectively, with increasing tilting. Thus, both factors may influence the antimicrobial efficacy. The VUV irradiation remained nearly constant. UV radiation leads to the formation of DNA lesions [36] which in consequence results in the induction of DNA repair mechanisms in bacteria but obviously also inactivates microorganisms [37]. Nevertheless, UV photons seem to have only minor influence on bacterial inactivation $[38,39]$. Furthermore, Schneider et al. $[40,41]$ described for a $\mathrm{He} / \mathrm{O}_{2}$ plasma 
a change in plasma effluent composition due to UV or, in particular, VUV photons, resulting in a synergistic effect with ROS and thereby a higher inactivation efficiency. This demonstrates once again the complexity of plasma and the thereby mediated processes.

In the herein introduced study, a first attempt was made to describe the manifold influencing parameters which are necessary to develop a contactless handheld device for plasma treatment. The microorganism S. aureus DSM 799/ATCC 6538 is a relevant wound pathogen and was chosen for this reason as a test organism. Nevertheless, in wounds it is not only one microorganism that is treated but rather it is a mixture of different species in different amounts. Thus, it has to be mentioned that other microorganisms may be easier or harder to inactivate [2]. This may influence the effective area and the treatment time.

The different parameters to detect the effective area of the kINPen ${ }^{\circledR}$ MED- $\beta$ were used for the design of a top unit for the device. The combined concept (Figure 13a) comprised a distance measurement via IR laser signal propagation time sensors with a focus on the working point in the effluent and an replaceable ring aperture. This-disposable or autoclavable, as requested-aperture can illuminate the effective area of the kINPen ${ }^{\circledR}$ MED- $\beta$ for the pre-defined treatment angle of, e.g., $0^{\circ}$ or $45^{\circ}$. Each aperture will be manufactured and provided according to the requirements of the medical personnel either for perpendicular or tilted treatment. Thus, the operator can adjust the selected aperture based on the wound accessibility and space for handling the device at the bedside. The provided measurements (inhibition zone, ROS, VUV, UV) led to a better understanding of the cocktail component contributions and distributions which allowed for the deduction of the dimensions (length and width) for the illumination of the effective area. However, the technical solution requires a defined spatial dimension at each given angle. Taking into account the complexity of the plasma cocktail components, a minimal effective area was defined to determine the illumination dimensions for the aperture at each given angle (Figure 13b). The resulting dimensions for the investigated treatment angles were calculated with an elliptical fit. A clear impact of the treatment area was shown over the investigated range of treatment angles. This motivates an adjusted aperture for application conditions. While the treatment angle of $0^{\circ}$ and $25^{\circ}$ changed the effective area from $107 \mathrm{~mm}^{2}$ to $132 \mathrm{~mm}^{2}$, the shape remained rather constant. For $50^{\circ}$ however, the shape changed significantly while the area increased only slightly $\left(140 \mathrm{~mm}^{2},+31 \%\right.$ in total $)$.

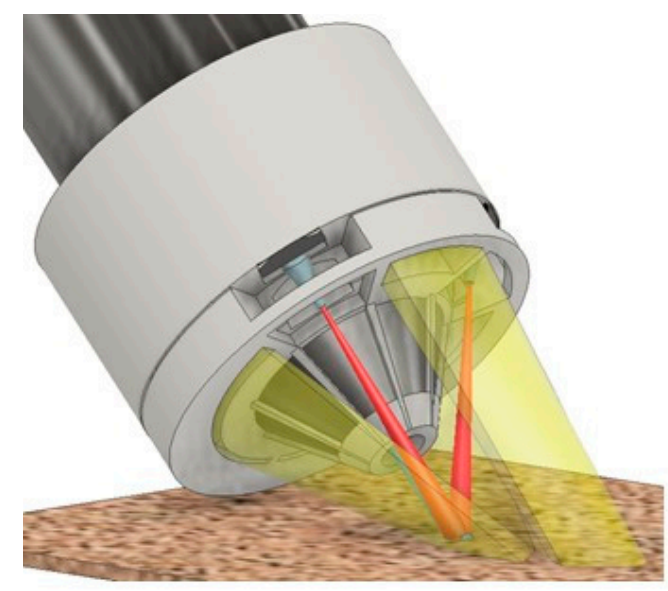

(a)

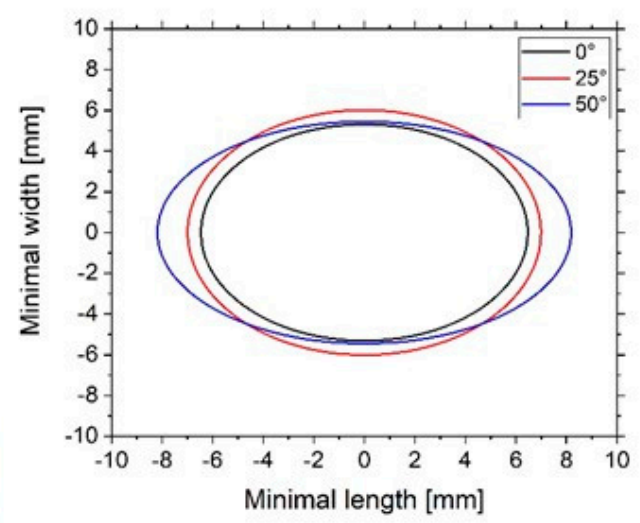

(b)

Figure 13. (a) Combined concept for sensors and illumination (with switched on LEDs); effective area with elliptical fit based on (b) minimal measured length and width.

A simplified laboratory prototype to test handling and user compliance was realized by adjusting four LEDs in a circular aperture to visualize the effective treatment area for a vertical treatment position (Figure 14a). The LEDs were positioned in such a way that, for the ideal treatment distance of $8.5 \mathrm{~mm}$, 
the LED spots were overlapping and a circular shape was formed, representing the dimensions of the ROS and inhibition zone tests (Figure 14b,c). The prototype device is operated with a battery and is initiated immediately by a press key positioned on top of the kINPen handheld applicator.

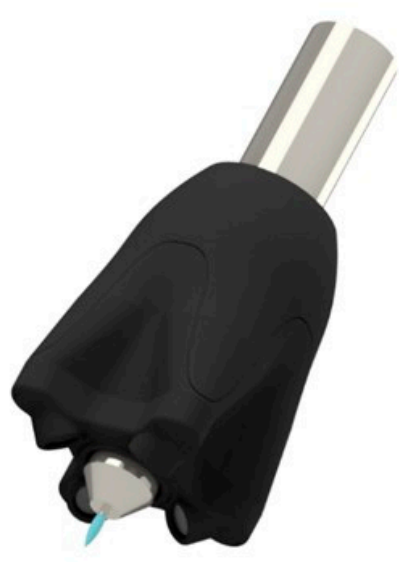

(a)

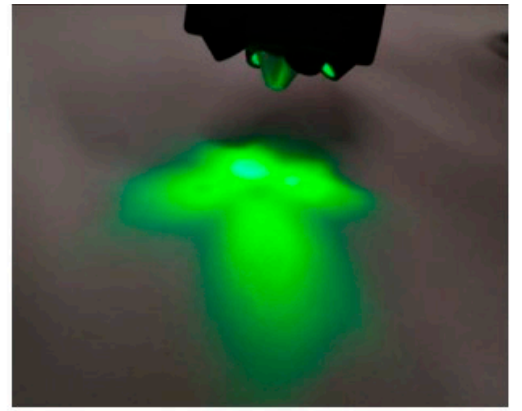

(b)

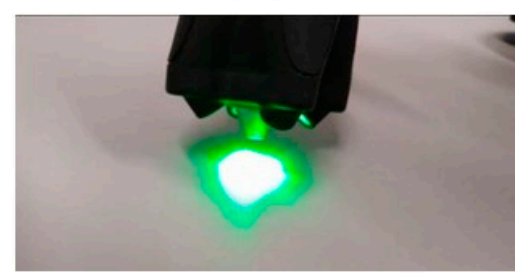

(c)

Figure 14. (a) Computer-aided design image of the simplified visualization tool, (b) picture of the four LED spots diverging due to high distance and tilting, (c) picture of the four LED spots converging at treatment distance.

\section{Conclusions}

The present study showed the development of a concept to replace a mechanical space holder with a sensory unit to facilitate handling the device at the bedside. At the same time, the novel system allows for adjusting the treatment angle to increase ergonomic comfort and wound accessibility. Thus, the influence of the treatment angle on the effective area was evaluated. A spot-like device, like a plasma jet, can adjust the delivered plasma cocktail by simply changing the incidence angle. In order to guide the user, a concept was developed to visualize the effective treatment area while considering the treatment distance.

The impact of the treatment angle onto the reactive oxygen species (ROS) distribution and the vacuum ultraviolet (VUV) and ultraviolet (UV) irradiation, as well as the antimicrobial efficacy, were evaluated as a kind of footprint. The resulting minimal effective area from each cocktail component can be used in the further course of such a sensor development to determine a template footprint of the plasma device at respective treatment angles.

Before the construction of a prototype as a next step, the proposed sensors should be tested under different environmental conditions, such as temperature, ambient light and humidity, to avoid unwanted dependencies. Furthermore, the sensors should be examined according to different surfaces, such as blood, secretion, tissue residues and hair, to exclude any reflections. A further conception for possible later automated procedures should be discussed under the premise that an interface is controlled via the sensory unit.

All this will result in a system which will ensure an optimal wound area coverage and thereby a more efficient and personalized treatment of patients.

Author Contributions: Conceptualization, T.G., B.N. and K.-D.W.; methodology, D.G., H.B., T.G. and V.H.; software, D.G., H.B.; validation, D.G., T.G. and V.H.; formal analysis, D.G., T.G. and V.H.; investigation, D.G., T.G. and V.H.; resources, T.G., B.N., K.-D.W., T.v.W. and V.H.; writing-original draft preparation, V.H., D.G. and T.G.; 
writing-review and editing, V.H., D.G., T.G., T.v.W., H.B., B.N. and K.-D.W.; supervision, T.G., B.N., H.B. and K.-D.W.; project administration, T.G., B.N. and K.-D.W. All authors have read and agreed to the published version of the manuscript.

Funding: This research received no external funding.

Acknowledgments: The authors acknowledge the work of Peter Holtz in preparing the UV and VUV tests as well as Doreen Anklam for technical assistance during the determination of antimicrobial efficacy.

Conflicts of Interest: The authors declare no conflict of interest.

\section{References}

1. Bekeschus, S.; Schmidt, A.; Weltmann, K.-D.; von Woedtke, T. The plasma jet kINPen-A powerful tool for wound healing. Clin. Plasma Med. 2016, 4, 19-28. [CrossRef]

2. Mann, M.S.; Tiede, R.; Gavenis, K.; Daeschlein, G.; Bussiahn, R.; Weltmann, K.-D.; Emmert, S.; von Woedtke, T.; Ahmed, R. Introduction to DIN-specification 91315 based on the characterization of the plasma jet kINPen MED. Clin. Plasma Med. 2016, 4, 35-45. [CrossRef]

3. Weltmann, K.-D.; Kindel, E.; Brandenburg, R.; Meyer, C.; Bussiahn, R.; Wilke, C.; von Woedtke, T. Atmospheric Pressure Plasma Jet for Medical Therapy: Plasma Parameters and Risk Estimation. Contrib. Plasma Phys. 2009, 49, 631-640. [CrossRef]

4. Gerling, T.; Helmke, A.; Weltmann, K.-D. Relevant Plasma Parameters for Certification. In Comprehensive Clinical Plasma Medicine; Metelmann, H.R., von Woedtke, T., Weltmann, K.-D., Eds.; Springer International Publishing: Basel, Switzerland, 2018; Volume 1, pp. 43-70.

5. Reuter, S.; von Woedtke, T.; Weltmann, K.-D. The kINPen-A review on physics and chemistry of the atmospheric pressure plasma jet and its applications. J. Phys. D Appl. Phys. 2018, 51, 233001. [CrossRef]

6. Lu, X.; Naidis, G.V.; Laroussi, M.; Reuter, S.; Graves, D.B.; Ostrikov, K. Reactive species in non-equilibrium atmospheric-pressure plasmas: Generation, transport, and biological effects. Phys. Rep. 2016, 630, 1-84. [CrossRef]

7. Privat-Maldonado, A.; Schmidt, A.; Lin, A.; Weltmann, K.-D.; Wende, K.; Bogaerts, A.; Bekeschus, S. ROS from Physical Plasmas: Redox Chemistry for Biomedical Therapy. Oxidative Med. Cell. Longev. 2019, 2019, 9062098. [CrossRef] [PubMed]

8. Laroussi, M.; Leipold, F. Evaluation of the roles of reactive species, heat, and UV radiation in the inactivation of bacterial cells by air plasmas at atmospheric pressure. Int. J. Mass Spectrom. 2004, 233, 81-86. [CrossRef]

9. Jablonowski, H.; von Woedtke, T. Research on plasma medicine-relevant plasma-liquid interaction: What happened in the past five years? Clin. Plasma Med. 2015, 3, 42-52. [CrossRef]

10. Daeschlein, G.; Scholz, S.; Arnold, A.; von Podewils, S.; Haase, H.; Emmert, S.; von Woedtke, T.; Weltmann, K.-D.; Jünger, M. In Vitro Susceptibility of Important Skin and Wound Pathogens Against Low Temperature Atmospheric Pressure Plasma Jet (APPJ) and Dielectric Barrier Discharge Plasma (DBD). Plasma Process. Polym. 2012, 9, 380-389. [CrossRef]

11. Daeschlein, G.; Napp, M.; von Podewils, S.; Lutze, S.; Emmert, S.; Lange, A.; Klare, I.; Haase, H.; Gümbel, D.; von Woedtke, T.; et al. In Vitro Susceptibility of Multidrug Resistant Skin and Wound Pathogens Against Low Temperature Atmospheric Pressure Plasma Jet (APPJ) and Dielectric Barrier Discharge Plasma (DBD). Plasma Process. Polym. 2014, 11, 175-183. [CrossRef]

12. Daeschlein, G.; Scholz, S.; Ahmed, R.; von Woedtke, T.; Haase, H.; Niggemeier, M.; Kindel, E.; Brandenburg, R.; Weltmann, K.-D.; Juenger, M. Skin decontamination by low-temperature atmospheric pressure plasma jet and dielectric barrier discharge plasma. J. Hosp. Infect. 2012, 81, 177-183. [CrossRef] [PubMed]

13. Kramer, A.; Lademann, J.; Bender, C.; Sckell, A.; Hartmann, B.; Münch, S.; Hinz, P.; Ekkernkamp, A.; Matthes, R.; Koban, I.; et al. Suitability of tissue tolerable plasmas (TTP) for the management of chronic wounds. Clin. Plasma Med. 2013, 1, 11-18. [CrossRef]

14. Metelmann, H.-R.; Vu, T.T.; Do, H.T.; Le, T.N.B.; Hoang, T.H.A.; Phi, T.T.T.; Luong, T.M.L.; Doan, V.T.; Nguyen, T.T.H.; Nguyen, T.H.M.; et al. Scar formation of laser skin lesions after cold atmospheric pressure plasma (CAP) treatment: A clinical long term observation. Clin. Plasma Med. 2013, 1, 30-35. [CrossRef]

15. Vandersee, S.; Richter, H.; Lademann, J.; Beyer, M.; Kramer, A.; Knorr, F.; Lange-Asschenfeldt, B. Laser scanning microscopy as a means to assess the augmentation of tissue repair by exposition of wounds to tissue tolerable plasma. Laser Phys. Lett. 2014, 11, 115701. [CrossRef] 
16. Ulrich, C.; Kluschke, F.; Patzelt, A.; Vandersee, S.; Czaika, V.A.; Richter, H.; Bob, A.; von Hutten, J.; Painsi, C.; Hüge, R.; et al. Clinical use of cold atmospheric pressure argon plasma in chronic leg ulcers: A pilot study. J. Wound Care 2015, 24, 196-203. [CrossRef] [PubMed]

17. Hilker, L.; von Woedtke, T.; Weltmann, K.-D.; Wollert, H.-G. Cold atmospheric plasma: A new tool for the treatment of superficial driveline infections. Eur. J. Cardio-Thoracic Surg. 2017, 51, 186-187. [CrossRef] [PubMed]

18. Schmidt, A.; Bekeschus, S.; Wende, K.; Vollmar, B.; von Woedtke, T. A cold plasma jet accelerates wound healing in a murine model of full-thickness skin wounds. Exp. Dermatol. 2017, 26, 156-162. [CrossRef]

19. Stratmann, B.; Costea, T.-C.; Nolte, C.; Hiller, J.; Schmidt, J.; Reindel, J.; Masur, K.; Motz, W.; Timm, J.; Kerner, W.; et al. Effect of Cold Atmospheric Plasma Therapy vs Standard Therapy Placebo on Wound Healing in Patients With Diabetic Foot Ulcers. JAMA Netw. Open 2020, 3, e2010411. [CrossRef]

20. Assadian, O.; Ousey, K.J.; Daeschlein, G.; Kramer, A.; Parker, C.; Tanner, J.; Leaper, D.J. Effects and safety of atmospheric low-temperature plasma on bacterial reduction in chronic wounds and wound size reduction: A systematic review and meta-analysis. Int. Wound J. 2018, 16, 103-111. [CrossRef]

21. Bernhardt, T.; Semmler, M.L.; Schäfer, M.; Bekeschus, S.; Emmert, S.; Boeckmann, L. Plasma Medicine: Applications of Cold Atmospheric Pressure Plasma in Dermatology. Oxidative Med. Cell. Longev. 2019, 2019, 873928. [CrossRef]

22. Schönebeck, R. kINPen MED ${ }^{\circledR}$. In Comprehensive Clinical Plasma Medicine; Metelmann, H.R., von Woedtke, T., Weltmann, K.-D., Eds.; Springer International Publishing: Basel, Switzerland, 2018; Volume 1, pp. 485-494.

23. Rakness, K.; Gordon, G.; Langlais, B.; Masschelein, W.; Matsumoto, N.; Richard, Y.; Robson, C.M.; Somiya, I. Guideline for Measurement of Ozone Concentration in the Process Gas from an Ozone Generator. Ozone Sci. Eng. 1996, 18, 209-229. [CrossRef]

24. Smit, H.G.J. Chemistry of the Atmosphere-Observations for Chemistry (In Situ). In Encyclopedia of Atmospheric Sciences, 2nd ed.; Academic press: Cambridge, MA, USA, 2015; pp. 372-378.

25. McAlpine, R.K. The rate of oxidation of iodide ion by hydrogen peroxide. J. Chem. Educ. 1945, $22,387$. [CrossRef]

26. Eguchi, W.; Tanigaki, M.; Mutoh, K.; Tsuchiya, H. The oxidation rate of iodide ion by nitrous acid in aqueous solution. Kagaku Kogaku Ronbunshu 1989, 15, 1109-1114. [CrossRef]

27. Yu, X.C.; Houtman, C.; Atalla, R.H. The complex of amylose and iodine. Carbohyd. Res. 1996, 292, $129-141$. [CrossRef]

28. Brandenburg, R.; Lange, H.; von Woedtke, T.; Stieber, M.; Kindel, E.; Ehlbeck, J.; Weltmann, K.-D. Antimicrobial Effects of UV and VUV Radiation of Nonthermal Plasma Jets. IEEE Trans. Plasma Sci. 2009, 37, 877-883. [CrossRef]

29. Hahn, V.; Brandenburg, R.; von Woedtke, T. DIN SPEC 91315: A First Attempt to Implement Mandatory Test Protocols for the Characterization of Plasma Medical Devices. In Comprehensive Clinical Plasma Medicine; Metelmann, H.R., von Woedtke, T., Weltmann, K.-D., Eds.; Springer International Publishing: Basel, Switzerland, 2018; Volume 1, pp. 511-516.

30. Daeschlein, G. Antimicrobial Activity of Plasma. In Comprehensive Clinical Plasma Medicine; Metelmann, H.R., von Woedtke, T., Weltmann, K.-D., Eds.; Springer International Publishing: Basel, Switzerland, 2018; Volume 1, pp. 113-125.

31. Iseni, S.; Schmidt-Bleker, A.; Winter, J.; Weltmann, K.-D.; Reuter, S. Atmospheric pressure streamer follows the turbulent argon air boundary in a $\mathrm{MHz}$ argon plasma jet investigated by OH-tracer PLIF spectroscopy. J. Phys. D Appl. Phys. 2014, 47, 152001. [CrossRef]

32. Wild, R.; Gerling, T.; Bussiahn, R.; Weltmann, K.-D.; Stollenwerk, L. Phase-resolved measurement of electric charge deposited by an atmospheric pressure plasma jet on a dielectric surface. J. Phys. D Appl. Phys. 2014, 47, 42001. [CrossRef]

33. Gerling, T.; Brandenburg, R.; Wilke, C.; Weltmann, K.-D. Power measurement for an atmospheric pressure plasma jet at different frequencies: Distribution in the core plasma and the effluent. Eur. Phys. J. Appl. Phys. 2017, 78, 10801. [CrossRef]

34. Nishime, T.M.C.; Wagner, R.; Kostov, K.G. Study of Modified Area of Polymer Samples Exposed to a He Atmospheric Pressure Plasma Jet Using Different Treatment Conditions. Polymers (Basel) 2020, 12, 1028. [CrossRef] 
35. Schmidt-Bleker, A.; Winter, J.; Bösel, A.; Reuter, S.; Weltmann, K.-D. On the plasma chemistry of a cold atmospheric argon plasma jet with shielding gas device. Plasma Sources Sci. Technol. 2016, 25, 015005. [CrossRef]

36. Ravanat, J.-L.; Douki, T.; Cadet, J. Direct and indirect effects of UV radiation on DNA and its components. J. Photochem. Photobiol. B Boil. 2001, 63, 88-102. [CrossRef]

37. Winter, T.; Bernhardt, J.; Winter, J.; Mäder, U.; Schlüter, R.; Weltmann, K.-D.; Hecker, M.; Kusch, H. Common versus noble Bacillus subtilis differentially responds to air and argon gas plasma. Proteomics 2013, 13, 2608-2621. [CrossRef] [PubMed]

38. Ehlbeck, J.; Schnabel, U.; Polak, M.; Winter, J.; von Woedtke, T.; Brandenburg, R.; von dem Hagen, T.; Weltmann, K.-D. Low temperature atmospheric pressure plasma sources for microbial decontamination. J. Phys. D Appl. Phys. 2011, 44, 13002. [CrossRef]

39. Lackmann, J.-W.; Bandow, J.E. Inactivation of microbes and macromolecules by atmospheric-pressure plasma jets. Appl. Microbiol. Biotechnol. 2014, 98, 6205-6213. [CrossRef] [PubMed]

40. Schneider, S.; Lackmann, J.-W.; Narberhaus, F.; Bandow, J.E.; Denis, B.; Benedikt, J. Separation of VUV/UV photons and reactive particles in the effluent of a $\mathrm{He} / \mathrm{O} 2$ atmospheric pressure plasma jet. J. Phys. D Appl. Phys 2011, 44, 295201-295217. [CrossRef]

41. Schneider, S.; Lackmann, J.-W.; Ellerweg, D.; Denis, B.; Narberhaus, F.; Bandow, J.E.; Benedikt, J. The Role of VUV Radiation in the Inactivation of Bacteria with an Atmospheric Pressure Plasma Jet. Plasma Process. Polym. 2012, 9, 561-568. [CrossRef]

(C) 2020 by the authors. Licensee MDPI, Basel, Switzerland. This article is an open access article distributed under the terms and conditions of the Creative Commons Attribution (CC BY) license (http://creativecommons.org/licenses/by/4.0/). 